\title{
Prevalence of mycoplasma gallisepticum in ross-308 broiler breeder through the contrast of serological assessments in Pakistan
}

\begin{abstract}
Chronic Respiratory disease in Poultry is mainly caused by Mycoplasma gallisepticum (MG). It causes huge economic loss to the poultry industry. The present study has been undertaken to determine the sero-prevalence of MG in Ross-308 broiler breeder farm in Punjab of Pakistan. A total of 103 commercial layer serum samples from 6 Ross-308 broiler breeder farms were subjected to indirect ELISA. From 103 serum samples, overall prevalence found $53.40 \%$ for commercial broiler breeder chickens. The highest (100\%) sero-prevalence of MG was recorded at 32 weeks and the lowest $(0 \%)$ was recorded at 68 weeks of commercial broiler breeder laying chicks. This study demonstrated high sero-prevalence of MG in Commercial broiler breeder. Therefore, routine monitoring of the commercial broiler breeder farms for MG infection should be recommended and mycoplasma control programmers must be strictly adhered.
\end{abstract}

Keywords: Broiler breeder, Mycoplasma gallisepticum, Sero-prevalence, ELISA
Short Communication

Volume 7 Issue I - 2018

\author{
Ahmad Hussain,' Adnan Yousaf, ${ }^{2}$ Aamerzish \\ Mushtaq, ${ }^{3}$ Mehar ul Nissa Rais ${ }^{4}$ \\ 'Department of Poultry Husbandry, Sindh Agriculture University, \\ Pakistan \\ ${ }^{2}$ Salman Poultry (Pvt) Limited, Pakistan \\ ${ }^{3}$ Faculty of Veterinary and Animals Sciences, PMAS-Arid \\ Agriculture University, Pakistan \\ ${ }^{4}$ Department of Agriculture Economics, Sindh Agriculture \\ Univeristy, Pakistan
}

Correspondence: Adnan Yousaf, Faculty of Animal Husbandry and Veterinary Sciences, Sindh Agriculture University, Tandojam, Pakistan; Email dr.adnan0I I@gmail.com

Received: August 23, 2017 | Published: February 23, 2018

Abbreviations: MG, mycoplasma gallisepticum; ELISA, enzyme-linked immunosorbent Assay; MS, Mycoplasma Synoviae; IBD, infectious bursal disease

\section{Introduction}

In Pakistan, the poultry industry has been persistently growing over the last decade. There are three distinct types of FAO classified poultry production system namely industrial integrated, commercial poultry production, and village or backyard production system. It is one of the most lucrative agro-based industries in Pakistan. There are approximately 1227 breeder farms and 10,000 layer farms established in different parts of the country. ${ }^{1}$ Among the respiratory diseases of poultry, Mycoplasmosis is a major one. Even though all the age groups of turkeys and chickens are susceptible to this disease, the occurrence of mycoplasmosis is higher in young birds when compare to adults. ${ }^{2,3}$ It is mainly caused by Mycoplasma gallisepticum (MG) and Mycoplasma synoviae (MS). MG infection results in increase Feed conversion ratio, poor weight gain and high mortality in broiler and reduced egg production in broiler breeder chicken thereby it causes huge economic loss to the poultry industry. ${ }^{4,5}$ Flock testing and culling is the best control measure for MG infection. ${ }^{1}$ Diagnosis of MG can be done by microbial culture, serological tests and molecular methods; ELISA is routinely used for the monitoring of determining antibody against MG. ${ }^{6}$ But for detecting the subclinical infection in the flock serology is the best tool. The seroprevalence of $\mathrm{Mg}$ in birds of different age groups, in different seasons, production status, sex, strain and flock sizes also vary. ${ }^{7}$ The aim of this study was to determine the seroprevalence of MG antibodies and to investigate the associated risk factors for the introduction and spread of the MG in broiler breeder chicken in Punjab at Pakistan.

\section{Materials and methods}

\section{Study area}

A total of 103 serum samples were obtained from 6 commercial broiler breeder farms in Punjab randomly were selected for screening against MG by indirect ELISA during the period of June 2017 to October 2017.

\section{Flock vaccination history}

The age group of the birds ranged from 32 to 68 weeks. Standard vaccination protocol against Marek's disease, Newcastle disease, IBD and Pox were followed in all the commercial broiler breeder birds. But all the birds were not vaccinated against MG.

\section{Blood samples collection}

Blood samples were collected aseptically and processed for serum separation as per standard methods. Then the sera samples were used for the serological study.

\section{Laboratory test procedure}

MG antigen coated plate (BioChek,UK) was used for the detection of antibody by indirect ELISA test. As per the manufacturer instruction the ELISA test has been carried out and the $\mathrm{S} / \mathrm{P}$ ratio was calculated. If the $\mathrm{S} / \mathrm{P}$ ratio is $\leq 0.5$ the sample is considered as negative and $\mathrm{S} / \mathrm{P}$ ratio of $>0.5$ considered as positive i.e. vaccination or infection with $\mathrm{MG}$.

\section{Statistical analysis}

Data regarding possible risk factors of $\mathrm{Mg}$ infection were entered into an excel spread sheet program (Excel 2017, Microsoft) for data 
management purposes. Data were imported to SAS version 9.2 (SAS Institute Inc., Cary, NC) to perform further statistical analysis.

\section{Results and discussion}

The results of the sero-prevalence of MG in commercial broiler breeder given in (Table 1). The highest (100\%) sero-prevalence of MG was recorded at 32 weeks and the lowest $(0 \%)$ was recorded at 68 weeks of commercial broiler breeder chicken. And overall sero-prevalence of MG found $53.40 \%$ for broiler breeder chickens. Previous surveys from France, Italy, Egypt and Jordan reported varying prevalence of $84 \%, 31 \%, 60 \%$ and $73.5 \%$ of MG by indirect ELISA respectively in commercial broiler breeder. ${ }^{8-11}$ Another survey in commercial broiler breeder chickens of Pakistan revealed 65.2\% sero-positivity of MG antibodies. ${ }^{1,12}$ In Bangladesh, 45.1\% sero-prevalence of MG was found in layer chickens. ${ }^{13}$ These above findings are concurrence with the present study and our results are very close in accordance with another finding obtained in south Punjab with a positivity rate of $54.4 \% \cdot{ }^{14,15}$ Regarding age-wise analysis, $100 \%$ prevalence of MG infection was seen in 32 weeks age group followed by $92.31 \%$ in 35 weeks layer chickens. In 68 weeks old layer chickens, the lowest seroprevalence of $0 \%$ was found. It revealed that when the age increased the prevalence of MG infection has been decreased. This denotes that the prevalence of Mycoplasma gallisepticum in commercial broiler breeder decreased with increasing age. Highest sero prevalence in the younger age group, maybe due to laying stress of the birds which might made the birds more prone to subclinical MG infections, and lowest rate of prevalence may be due to treatment that were used in flocks. The adult birds were treated prophylactically with anti-mycoplasmal drugs in the feed and drinking water. So the chances of mycoplasmal infection have been reduced, there by the prevalence of MG has been decreased in adult birds. In consequence, $M$. gallisepticum is prevalent in Pakistan. Therefore, routine monitoring of the commercial broiler breeder farms for MG infection should be recommended. In future studies on the current topic are therefore recommended.

Table I Prevalence of MG antibody in Ross-308 broiler breeder chicken through the contrast of ELISA

\begin{tabular}{llllll}
\hline Farms & $\begin{array}{l}\text { Age } \\
\text { (Weeks) }\end{array}$ & $\begin{array}{l}\text { No. of Sera } \\
\text { Tested }\end{array}$ & $\begin{array}{l}\text { No. of }+ \text { Ve } \\
\text { Samples }\end{array}$ & Positive \% & $\begin{array}{l}\text { Overall } \\
\text { Prevalence }\end{array}$ \\
\hline 1 & 35 & 13 & 12 & 92.31 & \\
2 & 43 & 16 & 14 & 87.5 & \\
3 & 50 & 29 & 14 & 48.27 & \\
4 & 32 & 13 & 13 & 100 & 0.534 \\
5 & 62 & 16 & 2 & 12.5 & \\
6 & 68 & 16 & 0 & 0 & \\
\hline
\end{tabular}

\section{Acknowledgments}

Authors are thankful to owner of commercial broiler breeder farms for cooperation.

\section{Conflict of interest}

There exists no conflict of interest.

\section{Author contributions}

All authors contributed equally.

\section{References}

1. Ahmad A, Rabbani M, Yaqoob T, et al. Status of IgG antibodies against Mycoplasma gallisepticum in non-vaccinated commercial poultry Breeder flocks. J Anim Plant Sci. 2008;18:61-63.

2. Alina W, Michaland M, Julita W, et al. Infections with Mycoplasma gallisepticum/synoviae in serological examination. Med Weter. 2000;56(4):240-244.

3. Barua SR, Prodhan AM, Islam A, et al. Study on Mycoplasma gallisepticum in chickens in selected areas of Bangladesh. $J$ Vet Med. 2006;4(2):141-142

4. Hossain KMM, Hossain MT, Yamato I, et al. Seroprevalence of Salmonella and Mycoplasma gallisepticum infection in Chickens in Rajshahi and surrounding districts of Bangladesh. Int J Biol. 2010;2(2):74-80

5. Jalilnia M, Movassagh MH. A study on causes of poultry carcasses condemnation in East Azerbaijan province (North West of Iran) poultry slaughterhouse. Annals Biologic Res. (2011);2(4):343-347.

6. Kempf I, Gesbertand F, Guittet M, et al. Experimental infection of chickens with an atypical Mycoplasma gallisepticumstrain: Comparison of diagnostic methods. Res Vet Sci. 1997;63(3):211-213.

7. Kleven SH, Noel NF. Mycoplasma synoviae infection In: Diseases of poultry, USA: Iowa State University Press; 2008. p. 845-856.

8. Ley DH. Mycoplasma gallisepticum infection In: Diseases of poultry, USA: Iowa State University Press; 2008. p. 805-833.

9. Ley DH, Yoder HW. Mycoplasma gallisepticum infectio.n In: Diseases of poultry, USA: Iowa State University Press; 1997. p. 194-207.

10. Mary B, Margaret L, Andrea E, et al. Detection of antibodies to Mycoplasma gallisepticum in egg yolk versus serum samples. J Clin Microbiol. 1991;29(12):2901-2903

11. Nunoya T, Yagihashi T, Tajima M, et al. Occurrence of kerato conjunctivitis apparently caused by Mycoplasma gallisepticum in layer chickens. Vet Pathol. 1995;32:11-18.

12. Osman KM, Aly MM, Amin ZMS, et al. Mycoplasma gallisepticum: an emerging challenge to the poultry industry in Egypt. Rev Sci Tech. 2009;28(3):1015-1023.

13. Reddy MR. Prevalence of Mycoplasma gallisepticum infection in indian poultry farms In: Proceedings of the 2nd International Conference on Animal \& Dairy Sciences, Hyderabad, India, 2014; 31 p.

14. Saad G, Dirgham A. The Use of Molecular Techniques in Isolation and Characterization of Mycoplasma gallisepticum from Commercial Chickens in Jordan. Int J Poult Sci. 2008;7(1):28-35.

15. Sarkar SK, Rahman MB, Rahman M, et al. Sero-Prevalence of Mycoplasma gallisepticum infection of Chickens in model breeder poultry farms of Bangladesh. Int J Poult Sci. 2005;4(1):32-35. 